\title{
International Standards of Trial Waiver Systems in Russian Criminal Procedure
}

\author{
Irina Chebotareva*, Olesia Pashutina, and Irina Revina \\ Department of Criminal Procedure and Criminalistics, Southwest State University, 50 let Oktyabrya, 94, Kursk, 305040, Russia
}

\begin{abstract}
Trial is a central part of any criminal procedure regardless of the type of the procedure and the procedural traditions. It is at this stage when the evidence is examined during an adversarial procedure and the issues of the guilt or innocence of a person accused of committing a crime and the assignment of punishment are considered. In 2018, the Committee on Legal Affairs and Human Rights of the Parliamentary Assembly of the Council of Europe paid attention to the fact that in many Member States of the Council of Europe and in the states Observers or having any other status in the Council of Europe or the Assembly, common criminal justice is gradually being replaced by various forms trial waiver. Based on Russian practices, the article examines trial waiver systems as a general concept that includes various national practices within individual states. It is characterized by various kinds of preferences exempted by the state for defendants who have pleaded guilty and waived their right to an adversarial trial; the study reviews positive and negative aspects of these practices as well as the minimum requirements they must comply with.
\end{abstract}

\section{Introduction}

In 2018, the Committee on Legal Affairs and Human Rights of the Parliamentary Assembly of the Council of Europe paid attention to the following. In many Member States of the Council of Europe and in the StatesObservers or states having any other status in the Council of Europe or the Assembly, common criminal justice is gradually being replaced by various forms of the trial waiver [1].

An empirical study conducted in more than 90 jurisdictions by a non-profit organisation 'Fair Trials International' shows that in many states, criminal trials are gradually being replaced by various forms of 'trial waiver systems', and in a number of countries only a minority of criminal sentences are given after a full-scale trial [2]. For example, in the USA, 'bargains' have almost completely replaced trials and are used in $97 \%$ of criminal cases. The researchers concluded that the trial becomes an archetype of criminal justice and begins to disappear. In many parts of the world, trials are replaced by legal regimes that encourage defendants to plead guilty and waive their right to a full trial.

The study revealed that currently, 66 countries from 90 involved in the research have similar practices, while in 1990 their number was only 19. The analysis of the distribution of these practices indicates that after being introduced in the state, they quickly begin to dominate. In Georgia, for example, $12.7 \%$ of cases were resolved through plea-bargain negotiation in 2005, and in 2012 their number grew to $87.8 \%$ of the cases. In the world, there has been a significant increase in the number of cases resolved through such procedures, and there is a clear trend to replace the traditional criminal procedure with different types of trial waiver systems.

The indicated trend to replace the trial is a matter of some concern. In his PACE report, B. Cillevičs draws attention to the rapid development of trial waiver systems in Central and Eastern European countries, which, in his opinion, is caused by the US influence on the introduction of 'negotiated guilty plea' existing in the American legal system, while reforming newly created democracies [1].

However, on September 17, 1987, at the 410th meeting of the Ministers of the Committee of Ministers of the Council of Europe, Recommendation No R (87) 18 'On the Simplification of Criminal Justice' was adopted by 18 member states. The need for its adoption was due to an increase in the number of criminal cases submitted to courts, and especially of those for which petty penalties were prescribed. This is due to problems caused by the length of legal proceedings (considering the fact that a delay in solving crimes that leads to discrediting of criminal law and affects the proper administration of justice).

Moreover, it was taken into account that delays in the administration of criminal justice can be eliminated not only by the allocation of special resources and the way they are used, but also by a more clear definition of the criminal policy priorities concerning the form and content of criminal procedures. In particular, it is possible to apply the principle of discretionary prosecution as well as using the so-called summary procedures, out-of-court settlement by the relevant

Corresponding author: cheb_irina@ mail.ru 
authorities as a possible alternative to prosecution. That is the so-called simplification of ordinary judicial procedures. It was assumed that these practices could be applied in cases when it comes to minor and mass crimes.

Among the forms of simplifying ordinary trial procedures, attention was also focused on hearings in the trial court of original or primary jurisdiction. It was noted that if the constitutional and legal traditions of the country allow 'guilty plea', in which the defendant must appear in court at an early stage of the proceedings in order to state whether he pleads or waives aside the charges against himself then the procedure or similar procedures should be introduced.

In such cases, the trial court of primary jurisdiction shall be able to decide whether to do without the full investigation process or only its part and immediately proceed to consider the identity of the offender, adjudicature and, if possible, resolve the issue of compensation (paragraph 6). The procedure of 'pleading guilty' should be performed in court at a public hearing. The defendant must plead guilty to the charge before a sentence is passed. Under this procedure, the judge should be able to hear both parties to the case.

\section{The concept of 'trial waiver'}

'Trial waiver' is a procedure which is not prohibited by law and in which defendants in criminal proceedings agree to plead guilty and/or to cooperate with the investigating authority in exchange for some benefit from the state, the most common form of which is a reduction in sentence and/or mitigated punishment [2]. In international documents, the mechanisms that allow such a practice are referred to as Trial Waiver Systems (TWS).

Within states, they can take different forms such as 'plea bargaining', 'pleading guilty', 'summary procedures', 'abbreviated trials', etc. The thing common to these systems is defendant's plea of guilty and waiver of full judicial law in return for a concession from the state. The characteristic features distinguishing a waiver of a trial from similar procedures (for example, alternatives to criminal prosecution) are (1) a defendant pleads guilty; (2) these deals lead to the conviction of the defendant; (3) the possibility of mitigating punishment when admitting guilt, pleading guilty, and expressing remorse does not have a discretionary form, represents clear, understandable and predictable reduction of punishment in exchange for defendant's cooperation and refusal of a court trial.

The term 'trial waiver' is an umbrella term that includes the terminology used in a national context when referring to specific jurisdictions.

Depending on the incentives that the state offers, there are four main types of trial waiver [3]:

(1) trial waiver resulting from the possibility of getting a sentence discount (the type of punishment and/or its size can be reduced) for the crime committed (in the criminal procedure of Russia, it is implemented as a special trial procedure [4], which will be discussed later in this article);

(2) trial waiver resulting from the fact that some facts of the crime remain uninvestigated or are not taken into account in exchange for the recognition by the defendant of others, less serious facts (there is no this type of trial waiver in Russian criminal procedure);

(3) trial waiver caused by the reduction of charges against the defendant (for example, death by negligence is charged instead of murder) and/or dismissal of charges (there is no this type of trial waiver in Russian criminal procedure);

(4) trial waiver resulted from the cooperation with the so-called privileged witnesses who provide evidence against others in exchange for lenient punishment for themselves. In the criminal procedure of Russia, it is implemented as a pre-trial agreement on cooperation (plea bargain) which will be discussed later in this article).

\section{Advantages and risks of trial waiver systems}

The advantages and risks of different types of trial waiver systems vary to a certain extent, but there are some common problems in these practices.

Obviously, trial waiver systems have distinct potential advantages:

(1) they save the resources that are necessary to fully and thoroughly investigate all alleged crimes and conduct a full fair trial in open court. Some less severe but more frequently committed offenses may not justify the expenses necessary for a full trial;

(2) they allow law resources to be allocated for fighting against clearly defined priority areas of criminal activity;

(3) they can help in the fight against organized crime, money laundering and other forms of complex crime, when prosecutors have the opportunity to offer 'deals' to potential 'privileged' cooperating witnesses;

(4) they allow defendants who plead guilty and are prepared to be punished to avoid a lengthy preliminary investigation that could limit their rights.

But trial waiver systems also have serious disadvantages $[5,6]$ :

(1) They are open to abuse by both the prosecution and the defence. The prosecutor may threaten the defendant with an unjustifiably harsh sentence if he or she refuse to confess, even if there is insufficient evidence. Boris Cillevičs, PACE rapporteur, draws attention to significant differences in criminal justice systems in Europe as well as between Europe and the USA; in particular, the broad prosecutors' powers, which, when there is no strong defence and an active role of the court, are fraught with risks of abuse when 'plea bargain' could turn into blackmail [1]. On the other hand, the defence attorney may persuade the prosecutor to accept partial confession of a defendant and ignore other, more serious criminal activities. As a rule, the first type of abuse is peculiar to young and poor offenders, while the second one is typical of wealthy white-collar 
criminals. Juridical literature draws attention to the high degree of danger that incentives for defendant's confession may be coercive [7]. It is obvious that in such a procedure, the possibility of convicting an innocent is the greatest danger;

(2) Relieving prosecutors from the necessity to bring the case to court; over time, widespread refusal of court trial affects the ability of authorities to conduct thorough investigations;

(3) the secrecy of 'plea bargaining' undermines public trust in the judicial system and the fair application of the law;

(4) plea bargaining increases the potential of the criminal justice system in case hearing and, as a result, increases the total number of criminal sentences. This increase may lead to the fact that the cost of detention of the increased number of prisoners could well negate the judicial resources saved by trial waiver.

Thus, on the one hand, these systems save resources and help in the fight against organized crime, allowing prosecutors to offer an 'agreement' to important witnesses. On the other hand, they have serious disadvantages since they are open to abuse by both the prosecution and the defence. The secrecy of such 'bargains' undermines public trust in the judiciary system and the fair, non-discriminatory application of the law.

\section{Human rights standards in trial waiver systems}

The above circumstances necessitated the development of appropriate safeguards by the Committee of Legal Affairs and Human Rights of the Council of Europe to enable states to take advantage of the potential advantages of trial waiver systems. Thus, this minimizes the threats to human rights that were recorded in PACE Resolution RES 2245 of 12.10.2018 "Deal Making in Criminal Proceedings: The Need for Minimum Standards for Trial Waiver Systems" [8].

These safeguards include: (1) compulsory involvement of a defence lawyer; (2) establishing a minimum standards for crime investigation that form the basis of the plea agreement; (3) disclosure of the results of the investigation, which requires judicial control of the key elements of the guilty plea agreement (including the credibility and voluntary nature of the confession). This also includes (4) the proportionality of the sanctions arising from the guilty plea agreement; (5) the prohibition of the waiver of the right to appeal; and (6) the control of bias and discrimination.

\section{Trial waiver systems in Russia}

In the Russian Federation, a special procedure for criminal trials [9] when the defendant pleads guilty with the charge (hereinafter referred to as the special trial procedure), as provided for in Chapter 40 of the Code of Criminal Procedure of the Russian Federation (hereinafter - CCP-RF) and a pre-trial agreement on cooperation (CCP-RF, Chapter 40.1) have the characteristic features peculiar to 'trial waiver systems'.

A special trial procedure can be applied to criminal cases in which the defendant pleads guilty and proof of quilt is not required. If the defendant agrees with the charge against him, there is no dispute between the parties of the prosecution and the defence, therefore, the court has the right to determine a sentence without examining the evidence of the defendant's guilt. Accepting the sentence is the right of the defendant. Based on this, the defendant has the right to make a choice whether his case will be examined according to regular procedure or according to the rules of the 'special trial procedure'.

When considering the case through a special trial procedure, the defendant may not be sentenced to more than two-thirds of the maximum term of punishment or the harshest type of punishment provided for the commission of a criminal offense.

Thus, expediting the consideration of short criminal causes in courts, reduces the burden on courts and creates an opportunity to focus efforts on cases that are evidently disputed. The application of such a procedure contributes to procedural saving of time and effort by courts and the parties in clear criminal cases. The special trial procedure, in a certain way, stimulates the behaviour of the defendant, allows him to avoid unjustified delays in resolving the criminal case when he pleads guilty, and guarantees less harsh punishment. In addition, when considering a criminal case through a special trial procedure, the convicted does not pay off court costs.

The Code of Criminal Procedure of the Russian Federation contains the grounds and conditions, the implementation of which allows the court to adjudge without a trial per standard procedure.

The ground of the special trial procedure is the defendant's motion.

However, the court has the right to adjudge without trial per standard procedure only if it is satisfied that (1) the defendant is aware of the nature and consequences of the motion; (2) the motion was filed voluntarily and after the defendant consulted with the defence lawyer (CCPRF, Art. 314(2)).

As the conditions $\mathrm{f}$ or the application of the special trial procedure, the legislator indicates: (1) the consent of the prosecutor or the private prosecutor as well as the victim to the criminal case consideration without a standard trial procedure; (2) a special trial procedure can be applied in criminal cases for crimes of small or medium gravity.

When considering criminal cases in a special trial procedure, the presence of the defendant, his defence lawyer, the public prosecutor (the prosecutor) or the private prosecutor is mandatory. During the trial, conducted as a special procedure, circumstances that characterize the personality of the defendant and circumstances mitigating or aggravating the punishment can be investigated.

An appeal against a sentence based on the results of a special trial procedure is allowed in case of violations of the criminal procedure legislation, improper application 
of the criminal law or unfairness of the sentence. In this case, the court of appeal does not have the right to investigate evidence supporting or refuting the charge, since they were not examined in the court of primary jurisdiction.

Summing up, it should be concluded that the grounds and conditions for the application of the special trial procedure are the defendant's consent with the charge against him and his motion for the application of the special trial procedure. A special trial procedure can be applied only for crimes of small or medium gravity. The consents of the public/private prosecutor and the victim are mandatory to apply special trial procedure. The guarantees of the defendant's rights are the preliminary consultation with the defence lawyer as well as the duty of the court to verify the voluntary nature of the motion submitted by the defendant, the defendant's awareness of the nature and consequences of the filed motion.

The pre-trial agreement on cooperation is another form of the trial waiver systems which exists in the Russian criminal procedure [10]. Its purpose is to fix in writing the obligation of the defendant (suspect) to facilitate the disclosure and investigation of the crime that he committed, with the provision of guarantees of mitigating criminal punishment in return. In the Russian law, this provision allows the convicted person who provided assistance to the investigation to get less harsh sentence (no more than half the maximum term of the harshest punishment for the crime committed).

One of the goals of introducing the institution of a pre-trial agreement on cooperation was countering organized crime.

A necessary condition for applying the consequences of the pre-trial agreement on cooperation is the fulfilment of the following requirements by the accused: defendant's active assistance to the process in the disclosure and investigation of the crime, exposure and criminal prosecution of other accomplices of the crime, and the search for property obtained as a result of the crime.

The suspect or the defendant shall submit a motion for pre-trial agreement on cooperation to the prosecutor in writing. In the plea, he indicates what actions he shall undertake in order to facilitate the investigation and the disclosure of the crime, the exposure and criminal prosecution of other accomplices of the crime, and the search for property obtained as a result of the crime.

The defendant's motion may be dismissed.

The trial and the sentencing of the defendant, with whom a pre-trial agreement on cooperation was made, are carried out through a special trial procedure, considered above with the only difference that the consent of the victims to consider the case is not required.

During the consideration of the criminal case by the court, the nature and limits of the defendant's assistance to the investigation and disclosure of the crime, the exposure and criminal prosecution of other accomplices of the crime, the search for property obtained as a result of the crime are investigated. The importance of the cooperation with the defendant for the investigation and disclosure of the crime, the exposure and criminal prosecution of other accomplices of the crime, the search for property obtained as a result of the crime is taken into account. The crimes or criminal cases revealed or initiated as a result of cooperation with the defendant are considered. The degree of threat to which the defendant, his close relatives, relatives and close persons were subjected as a result of the defendant's cooperation with the prosecution as well as the circumstances characterizing the personality of the defendant, and circumstances mitigating and aggravating the punishment are examined.

The institution of a pre-trial agreement on cooperation is a specific legally encouraged procedural form of cooperation of a person who is prosecuted with law enforcement agencies.

In 2010, a total of 1,027.35 thousand criminal cases were heard, of which 553.1 thousand were heard in a special trial procedure (54\%). In 2014, 598.81 thousand criminal cases out of 902.51 thousand were heard in a special trial procedure $(66 \%)$. In 2017 , a total number of criminal cases were 854.1 thousand, and 594.32 thousand were heard in a special trial procedure $(70 \%)$ 276,064 guilty verdicts were handed down in a special trial procedure with the consent of the defendant with the charges brought against him. This is $52 \%$ of the total number of convicted persons (in 2019 - 354,864, or $59.3 \%$ ) [11].

As provided for by in Chapter 40.1 of CCP-RF (the pre-trial agreement on cooperation), approximately $0.3 \%$ were heard in 2011 , slightly less than $0.5 \%$ - in 2015 , and slightly more than $0.5 \%$ - in 2017. In 2019, 620,054 people were convicted. 3009 people entered into a pretrial agreement with the investigation $(0.5 \%)$.

\section{Conclusion}

Thus, on the one hand, trial waiver systems save resources and help in the fight against organized crime, allowing prosecutors to offer 'agreement' to important witnesses. On the other hand, they have serious disadvantages, since they are open to abuse by both the prosecution and the defence. The secrecy of such bargains undermines public confidence in the judiciary system and the fair, non-discriminatory application of the law.

These circumstances necessitate providing guarantees that allow states to take potential advantages of trial waiver systems, minimizing the threat to human rights. These guarantees include (1) compulsory involvement of a defence lawyer; (2) establishing minimum standards for crime investigation that form the basis of the plea agreement; (3) disclosure of the results of the investigation, which requires judicial control of the key elements of the guilty plea agreement (including the credibility and voluntary nature of the confession). There is the proportionality of the sanctions arising from the guilty plea agreement; the prohibition of the waiver of the right to appeal; and the control of bias and discrimination.

In the Russian Federation, a special procedure for criminal trials when the defendant pleads guilty with the 
charge as provided for in Chapter 40 of the Code of Criminal Procedure of the Russian Federation and a pretrial agreement on cooperation (CCP-RF, Chapter 40.1) have the characteristic features peculiar to 'trial waiver systems'.

The grounds and conditions for the application of the special trial procedure are the defendant's consent with the charge against him and his motion for the application of the special trial procedure. A special trial procedure can be applied only for crimes of small or medium gravity. The consents of the public/private prosecutor and the victim are mandatory to apply special trial procedure. The guarantees of the defendant's rights are the preliminary consultation with the defence lawyer as well as the duty of the court to verify the voluntary nature of the motion submitted by the defendant, the defendant's awareness of the nature and consequences of the filed motion.

The institution of a pre-trial agreement on cooperation is a specific legally encouraged procedural form of cooperation of a person who is prosecuted with law enforcement agencies.

\section{Acknowledgments}

The reported study was funded by RFBR, project number 20-011-00858.

\section{References}

1. Report Committee on Legal Affairs and Human Rights PACE 'Deal making in criminal proceedings: the need for minimum standards for trial waiver systems' Doc. No. 14618 (19 Sept. 2018). Retrieved from: http://assembly.coe.int/nw/xml/XRef/XrefDocDetails-EN.asp?FileID=25041\&lang=EN

2. The Disappearing Trial: A global study into the spread and growth in trial waiver systems. Retrieved from: https://www.fairtrials.org/publication/ disappearing-trial-report

3. J. Russell, N. Hollander, New J. Eur. Crim. Law, 8, 309 (2017)

4. T.K. Ryabinina, Proceedings of the Southwest State University, 21, 182 (2017)

5. R.K. Helm, J. Law Soc., 46, 423 (2019)

6. H.M. Caldwell, Cath. U. L. Rev., 61, 63 (2012)

7. L. Bachmaier, Eur. J. Crime Crim. Law Crim. Justice, 26, 236 (2018)

8. Resolution PACE 'Deal making in criminal proceedings: the need for minimum standards for trial waiver systems' Res 2245 (12 Oct. 2018). Retrieved from: http://assembly.coe.int/nw/ xml/XRef/Xref-DocDetailsEN.asp?FileID=25188\&lang=EN

9. I. Pisarevskiy, Tomsk State University Journal, 404, 169 (2016)

10. V.V. Kolesnik, Legal Science and Practice: Journal of Nizhniy Novgorod Academy of the Ministry of Internal Affairs of Russia, 36, 100 (2016)

11. Overview of the activities of courts of General jurisdiction and magistrates in Russia 2010, 2011, 2014, 2015, 2017. Judicial Department of the Supreme Court of the Russian Federation. Retrieved from: http://www.cdep.ru/index.php?id=80 